\title{
Prevalence of asthma symptoms based on the European Community Respiratory Health Survey questionnaire and FENO in university students: gender differences in symptoms and FeNO
}

\author{
Tamotsu Ishizuka ${ }^{1 *}$, Shinichi Matsuzaki ${ }^{1}$, Haruka Aoki ${ }^{1}$, Masakiyo Yatomi ${ }^{1}$, Yosuke Kamide ${ }^{1}$, Takeshi Hisada',
} Takahiro Tsuburai ${ }^{2}$, Kunio Dobashi ${ }^{3}$, Kihachi Ohshima ${ }^{4}$, Kazuo Akiyama ${ }^{2}$ and Masatomo Mori ${ }^{1}$

\begin{abstract}
Background: The fractional concentration of nitric oxide in exhaled air (FENO) is used as a biomarker of eosinophilic airway inflammation. FENO is increased in patients with asthma. The relationship between subjective asthma symptoms and airway inflammation is an important issue. We expected that the subjective asthma symptoms in women might be different from those in men. Therefore, we investigated the gender differences of asthma symptoms and FENO in a survey of asthma prevalence in university students.

Methods: The information about asthma symptoms was obtained from answers to the European Community Respiratory Health Survey (ECRHS) questionnaire, and FENO was measured by an offline method in 640 students who were informed of this study and consented to participate.

Results: The prevalence of asthma symptoms on the basis of data obtained from 584 students (266 men and 318 women), ranging in age from 18 to 24 years, was analyzed. Wheeze, chest tightness, an attack of shortness of breath, or an attack of cough within the last year was observed in 13.2\% of 584 students. When 38.0 ppb was used as the cut-off value of FENO to make the diagnosis of asthma, the sensitivity was $86.8 \%$ and the specificity was $74.0 \%$. FENO was $\geq 38.0$ $\mathrm{ppb}$ in $32.7 \%$ of students. FeNO was higher in men than in women. The prevalence of asthma symptoms estimated by considering FENO was 7.2\%; the prevalence was greater in men (9.4\%) than women (5.3\%). A FENO $\geq 38.0$ ppb was common in students who reported wheeze, but not in students, especially women, who reported cough attacks.
\end{abstract}

Conclusions: The prevalence of asthma symptoms in university students age 18 to 24 years in Japan was estimated to be $7.2 \%$ on the basis of FENO levels as well as subjective symptoms. Gender differences were observed in both FeNO levels and asthma symptoms reflecting the presence of eosinophilic airway inflammation.

Trial registration number: UMIN000003244

\section{Background}

Bronchial asthma is a chronic inflammatory disease characterized by reversible airway limitation and airway hyperreactivity. Clinically, patients with asthma have repeated symptoms, such as wheeze, shortness of breath, or cough, especially at night or early morning. When we make a

\footnotetext{
* Correspondence: tamotsui@showa.gunma-u.ac.jp

'Department of Medicine and Molecular Science, Gunma University Graduate School of Medicine, 3-39-15 Showa-machi, Maebashi 371-8511, Japan

Full list of author information is available at the end of the article
}

diagnosis of asthma, it is helpful to expect that the patients have eosinophilic airway inflammation although asthma is not always associated with eosinophilic inflammation. In recent years, the fractional concentration of nitric oxide in exhaled air (the fraction of exhaled nitric oxide, FENO) has been used as a biomarker of eosinophilic inflammation in the airway [1-3]. In fact, FENO is increased in asthmatic patients compared to healthy subjects [4]. Measurements of FENO are useful for making the diagnosis of asthma, and its sensitivity and specificity as a marker for the diagnosis are relatively high [5-8]. There are two procedures

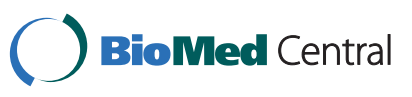

(c) 2011 Ishizuka et al; licensee BioMed Central Ltd. This is an Open Access article distributed under the terms of the Creative Commons Attribution License (http://creativecommons.org/licenses/by/2.0), which permits unrestricted use, distribution, and reproduction in any medium, provided the original work is properly cited. 
for FENO measurements: online and offline. Exhaled gas is collected in a reservoir and subsequently analyzed for nitric oxide (NO) concentrations in offline measurements [9]. Particularly in epidemiologic studies, offline measurement might be superior to online measurement because it is economical and makes it easy to measure a number of samples in a short time $[10,11]$.

Worldwide epidemiological surveys on adult asthma have been mainly performed using the European Community Respiratory Health Survey (ECRHS) questionnaire [12-17]. Asthma symptoms including wheezing, a nocturnal feeling of tightness in the chest, a nocturnal attack of shortness of breath, or a nocturnal attack of cough in the ECRHS questionnaire are consistent with asthma, but certainly not specific for asthma. Moreover, we cannot guess the degree of eosinophilic airway inflammation in each subject based on the information obtained from a questionnaire. Therefore, we think that the combination of FENO measurements and the questionnaire about asthma symptoms might make it possible to develop a more objective estimate in epidemiological studies of asthma prevalence.

In this study, an analysis of the prevalence of asthma symptoms in university students was attempted using both the ECRHS questionnaire and FENO measured by an offline method. Additionally, we tried to investigate the gender differences in FENO levels and asthmatic symptoms.

\section{Methods}

\section{Subjects}

This study was approved by the Institutional Review Board of Gunma University Hospital, on January 27, 2010 and registered with UMIN-CTR on February 13, 2010 (ID number: UMIN000003244). Gunma University students who participated in the study were asked to fill out an ECRHS questionnaire (Japanese version) [18], and breath samples were obtained. The study was performed from April 1 to 9, 2010 when physical examinations for students were done. The flowchart of this clinical study is shown in Figure 1. We put up a notice that asked for participation in our clinical study. Of the 3247 students who underwent physical examinations, 643 students intended to take part in this study and visited our room. These 643 students were informed of the study in detail. The 640 students consented to participate in the study and signed the consent form. The receiver operating characteristic (ROC) curve was produced using FENO data obtained from 504 samples out of 640 samples (Additional file 1). Samples obtained from 38 students who had suffered from asthma and had wheezing for the last year were used as samples from an asthma group, and samples obtained from 466 students who had not suffered from asthma, did not have any asthmatic symptoms, and had not experienced chronic bronchitis-like symptoms were used as samples from a non-asthma group. When 38.0 ppb was used as the cut-off value to classify the subjects in this study, the sensitivity was $86.8 \%$ and the specificity was $74.0 \%$. To investigate the prevalence of asthma symptoms in the specified generation, we used the data obtained from 584 Gunma University students (266 male and 318 female students; age range, 18 to 24 years; mean \pm SD age, $19.6 \pm 1.6$ years) and did not use the data from 56 students who were $\geq 25$ years old in this investigation. The prevalence of asthma symptoms was analyzed based on the previous 1-year period.

\section{Methods}

The original 9 main questions containing sub-questions translated into Japanese in the Japanese version of the ECRHS a 1-page questionnaire were used in this study $[18,19]$. Breath samples were obtained using an offline kit produced by the Center for Environmental Information Science (Tokyo, Japan) to measure FENO under the same conditions as with online measurement $[10,11]$. In this device, the expiratory flow rate is adjusted to $50 \mathrm{~mL} / \mathrm{s}$ when subjects exhale at $1.5 \mathrm{kPa}$ oral pressure after inhaling deeply. The adjustment was performed with a variable flux pump (SIBATA, Soka, Japan). A disposable paper mouthpiece and a viral and bacterial filter were connected to a plastic mouthpiece adaptor with a pressure gauge, followed by a plastic T-tube with a resistance valve and a bag reservoir for collecting exhaled gas. A 1.5-L Mylar bag (Sievers, Boulder, CO) was used for the reservoir bag. During expiration, subjects were asked to maintain a constant mouth pressure $(1.5 \mathrm{kPa})$ by looking at a pressure gauge. Air exhaled in the first 5 seconds $(250 \mathrm{~mL})$ was discarded, and the air exhaled between 5 to 10 seconds $(250 \mathrm{~mL})$ was collected in the Mylar bag. Samples obtained in bags were stored at $4^{\circ} \mathrm{C}$ to overcome error induced by sample storage and FENO was measured within 8 hours using a chemiluminescence analyzer (NOA 280, Sievers).

\section{Statistical analysis}

Statistical analysis was performed using SPSS software (SPSS Japan Inc., Tokyo, Japan). Differences in percentages between two groups were analyzed using the chi-square test, and differences in means between two groups were analyzed using Student's $t$-test.

\section{Results}

1. Gender differences in FeNO and symptoms, especially wheeze and nocturnal cough attacks

The students ranged in age from 18 to 24 . The mean \pm SD FeNO in 584 students was $36.7 \pm 29.6 \mathrm{ppb}$, and was $\geq$ $38.0 \mathrm{ppb}$ in 191 (32.7\%) of 584 students. Among the 266 male students, the mean FENO was $43.6 \pm 34.0 \mathrm{ppb}$, and was $\geq 38.0 \mathrm{ppb}$ in 111 (41.7\%) of 266 students. Among 


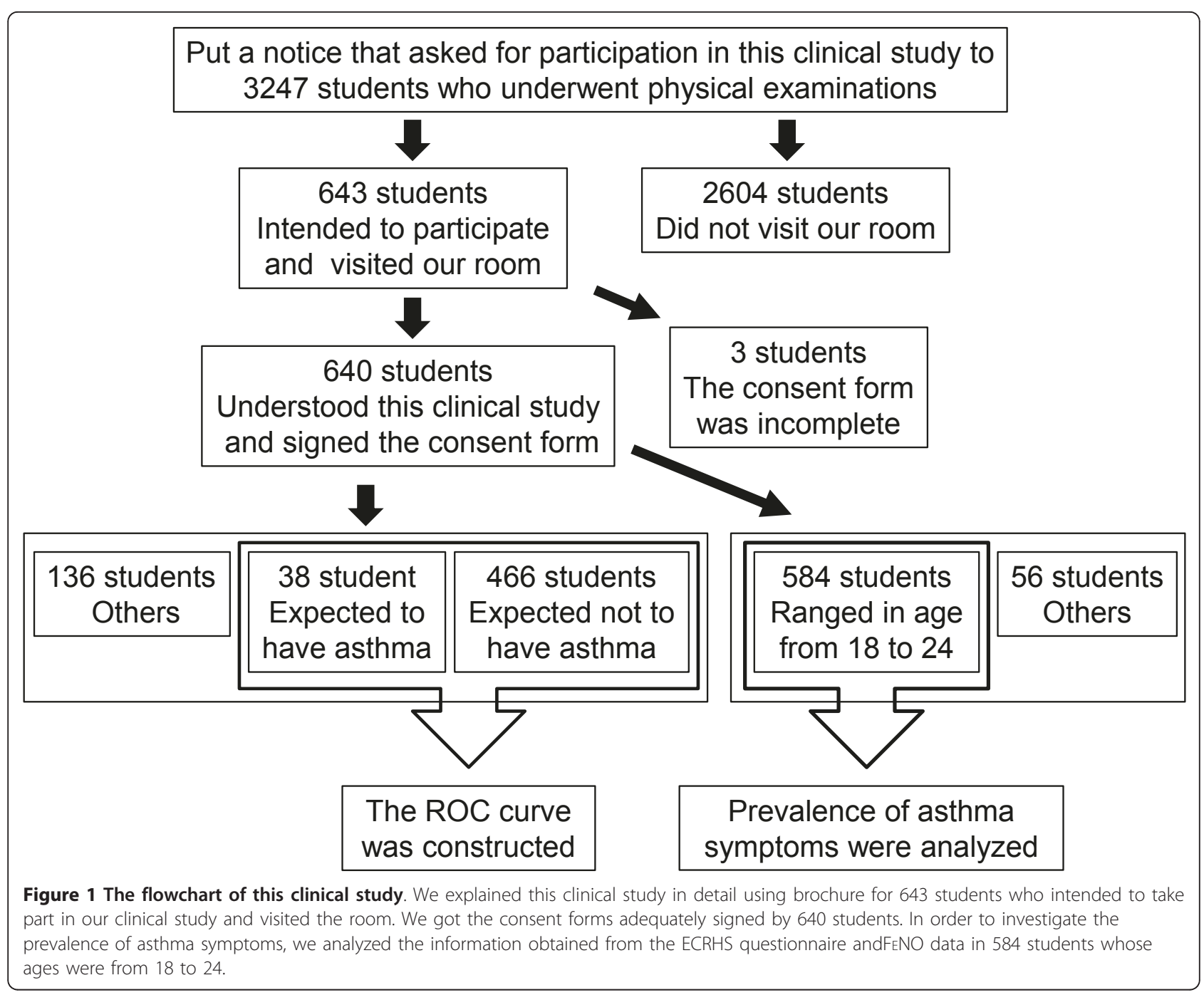

the 318 female students, the mean FENO was $31.0 \pm 24.0$ $\mathrm{ppb}$, and was $\geq 38.0 \mathrm{ppb}$ in 80 (25.2\%) of 318 students. FENO levels and the percentage of students whose FENO was $\geq 38.0 \mathrm{ppb}$ were significantly higher in men than in women $(p<0.01$, Figure 2$)$.

FENO was $\geq 38.0 \mathrm{ppb}$ in 38 (24 men and 14 women) of the 50 students ( 27 men and 23 women) who had experienced wheezing. It was $\geq 38.0 \mathrm{ppb}$ in 7 (3 men and 4 women) of 24 students ( 5 men and 19 women) who had a nocturnal attack of cough. The percentages of subjects whose FENO was $\geq 38.0$ ppb were $76.0 \%$ of the subjects who had wheezing and $29.2 \%$ of those with a nocturnal attack of cough. The percentage of students whose FENO was $\geq 38.0 \mathrm{ppb}$ was smaller in those who had nocturnal attacks of cough than in those who had experienced wheezing (Figure 3A). The percentage of students whose FENO was $\geq 38.0 \mathrm{ppb}$ in those who had experienced wheezing was $88.9 \%$ in men and $60.9 \%$ in women; the difference was significant $(p<0.05)$ (Figure 3B). Although a nocturnal attack of cough was relatively frequent in women, only 4 (21.1\%) of 19 female students who had nocturnal attacks of cough had a FENO $\geq 38.0 \mathrm{ppb}$ (Figure $3 \mathrm{C})$.

\section{Asthmatic symptoms in University students based on the ECRHS questionnaire}

Of the 584 students, 77 (13.2\%) answered that they had any asthmatic symptoms, including wheezing, a nocturnal feeling of tightness in the chest, a nocturnal attack of shortness of breath, or a nocturnal attack of cough in the last year (Figure 4A). Thus, the maximum prevalence of asthma symptoms in Gunma University students was $13.2 \%$. Thirty-three (12.4\%) of 266 male students and 44 (13.8\%) of 318 female students had asthmatic symptoms. The percentage of students who had asthmatic symptoms was not significantly different between men and women. Of the 584 students, $50(8.6 \%)$ reported wheezing, 11 (1.9\%) had a nocturnal feeling of tightness in the chest, 

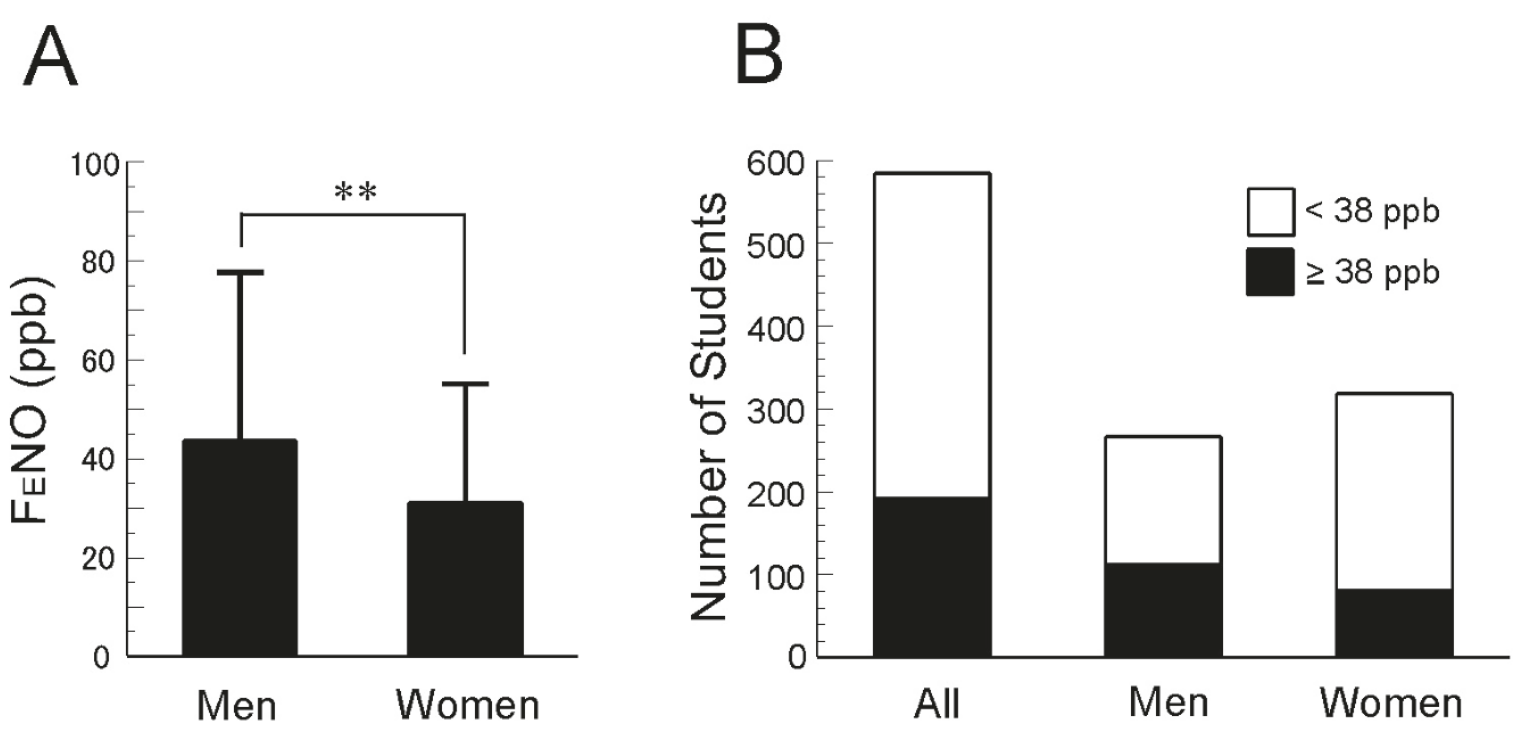

Figure 2 A gender difference in FENO and the percentage of students whose FENO was $\geq 38.0$ ppb. In the 584 students ranging in age from 18 to 24 years, FENO was significantly higher in men than in women (**, $p<0.01$ ) (A). Overall, $32.7 \%$ of the 584 students, including $41.2 \%$ of male students and $25.2 \%$ of female students, had FENO $\geq 38.0 \mathrm{ppb}$. The percentage of men was significantly higher than that of women ( $p<0.01$ ) (B).

$6(1.0 \%)$ had a nocturnal attack of shortness of breath, and $24(4.1 \%)$ had a nocturnal attack of cough within the last year. Overall, $10.2 \%$ (27 of 266) of men and 7.2\% (23 of 318 ) of women had wheezing. On the other hand, significantly more women $(6.0 \%, 19$ of 318$)$ had a nocturnal attack of cough than men $(1.9 \%, 5$ of $266 ; p<0.05)$.

\section{The prevalence of asthma symptoms based on the ECRHS questionnaire and FENO measurement}

FENO was over $38.0 \mathrm{ppb}$ in 42 (25 men and 17 women) of the 77 students who had any asthmatic symptoms. Thus, the prevalence of asthma symptoms over 1 year in Gunma University students was $7.2 \%$ of 584 students, based on our definition of a predictive FENO and the information about symptoms obtained from the ECRHS questionnaire (Figure 4B). As a result of this analysis, the prevalence of asthma symptoms was greater in men (9.4\%) than in women (5.3\%).

\section{Past history of asthma and current subjective symptoms} A total of 103 students (58 men and 45 women; $17.6 \%$ of 584 students) answered that they had suffered from asthma, including $21.8 \%$ of 266 male students and $14.2 \%$ of 318 female students; the difference between men and women was significant $(p<0.05)$ (Figure 5A). Thirty six (35.0\%) of 103 students who suffered from asthma still had asthmatic symptoms (Figure 5B). Overall, 19 (32.8\%) of 58 male students and 17 (37.8\%) of 45 female students with a past history of asthma still felt any asthmatic symptoms. Of the 103 students who had suffered from asthma, 16 were being treated at the time of the survey, of whom only 3 had been treated well and had no asthmatic symptoms within the last year. Only $36.1 \%$ of the 36 students with current asthmatic symptoms and a past history of asthma were being treated medically at the time of the survey, and the other $63.9 \%$ were not being treated. A total of 41 students ( 14 men and 27 women) who did not have a past history of asthma and did not recognize themselves as having asthma had asthmatic symptoms within the last year. They accounted for $7.0 \%$ of the 584 students. Even if the students did not have a past history of asthma, they were also considered to have asthma when they had any asthmatic symptoms within the last year and their FENO was $\geq 38.0$ ppb. FENO was $\geq$ $38.0 \mathrm{ppb}$ in 11 (26.8\%; 7 men and 4 women) of 41 students. A significantly greater percentage of men $(50.0 \%)$ than women $(14.8 \%)$ had a FENO $\geq 38.0$ ppb $(p<0.05)$ (Figure 5C).

\section{Nasal allergies including hay fever}

Of the 584 students, 314 (53.8\%) answered "Yes" to the question "Do you have any nasal allergies including hay fever?" FENO was significantly higher in students who had any nasal allergies including hay fever than in other students $(41.4 \pm 32.2$ ppb vs. $31.3 \pm 25.4 \mathrm{ppb}$, mean \pm $\mathrm{SD}, p<0.01)$. The percentage of students who had any nasal allergies did not differ between men (54.9\%, 146 of $266)$ and women $(52.8 \%, 168$ of 318$)$.

\section{Discussion}

The gold standard of asthma diagnosis is obstructive lung disease with airway reversibility, or airway reactivity 
of male than female students $(p<0.05)$ (B). Nocturnal attacks of cough were observed significantly more often in women than in men $(p<0.05)$. Among students with nocturnal attacks of cough, FENO was $\geq 38.0 \mathrm{ppb}$ in a smaller percentage of female than male students (C).

confirmed by challenge testing, not history or symptoms. Information obtained from the questionnaire which only asks asthmatic symptoms and history of asthma is not enough to make diagnosis of asthma, because clinical suspicion of asthma should be confirmed by objective measures of pulmonary function [20]. Strictly, current asthma symptoms on the ECRHS questionnaire are not equal to clinically current symptoms because this questionnaire is designed to detect asthma symptoms over 1 year. Although we must also emphasize that the ROC curve was constructed only to classify subjects of this study and that it was not constructed to help diagnose asthma, a previous study using the same offline method proposed that the optimal cutoff value of $\mathrm{F}_{\mathrm{ENO}}$ was $38.0 \mathrm{ppb}$ for detecting allergic airway inflammation in an adult population [10]. This cut-off value was equal to that we used in this study.

In our survey, two symptoms, wheeze and a nocturnal attack of cough were most frequently reported. FENO was $\geq 38.0 \mathrm{ppb}$ in more than $75 \%$ of subjects who had wheeze. In those students who had experienced wheezing, the percentage whose FENO was $\geq 38.0 \mathrm{ppb}$ was significantly higher in men than in women. This suggests that wheeze as a subjective symptom correlates with the presence of chronic eosinophilic airway inflammation especially in men. In fact, wheeze is the most
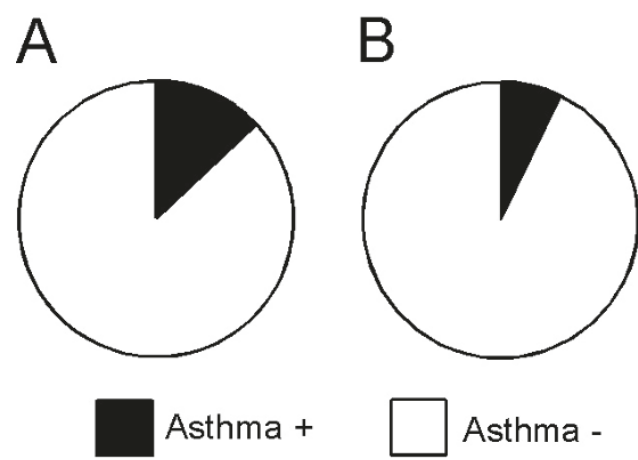

Figure 4 The prevalence of asthma symptoms in students ranging in age from 18 to 24 years. Overall, 77 (13.2\%) of 584 students experienced any asthmatic symptoms within the last year. One-year prevalence of asthma symptoms in university students ranging in age from 18 to 24 years was expected to be $13.2 \%$ at a maximum (A). FENO was over 38.0 ppb in 42 of the 77 students. The prevalence of asthma symptoms was estimated to be $7.2 \%$ by considering FENO levels (B). 


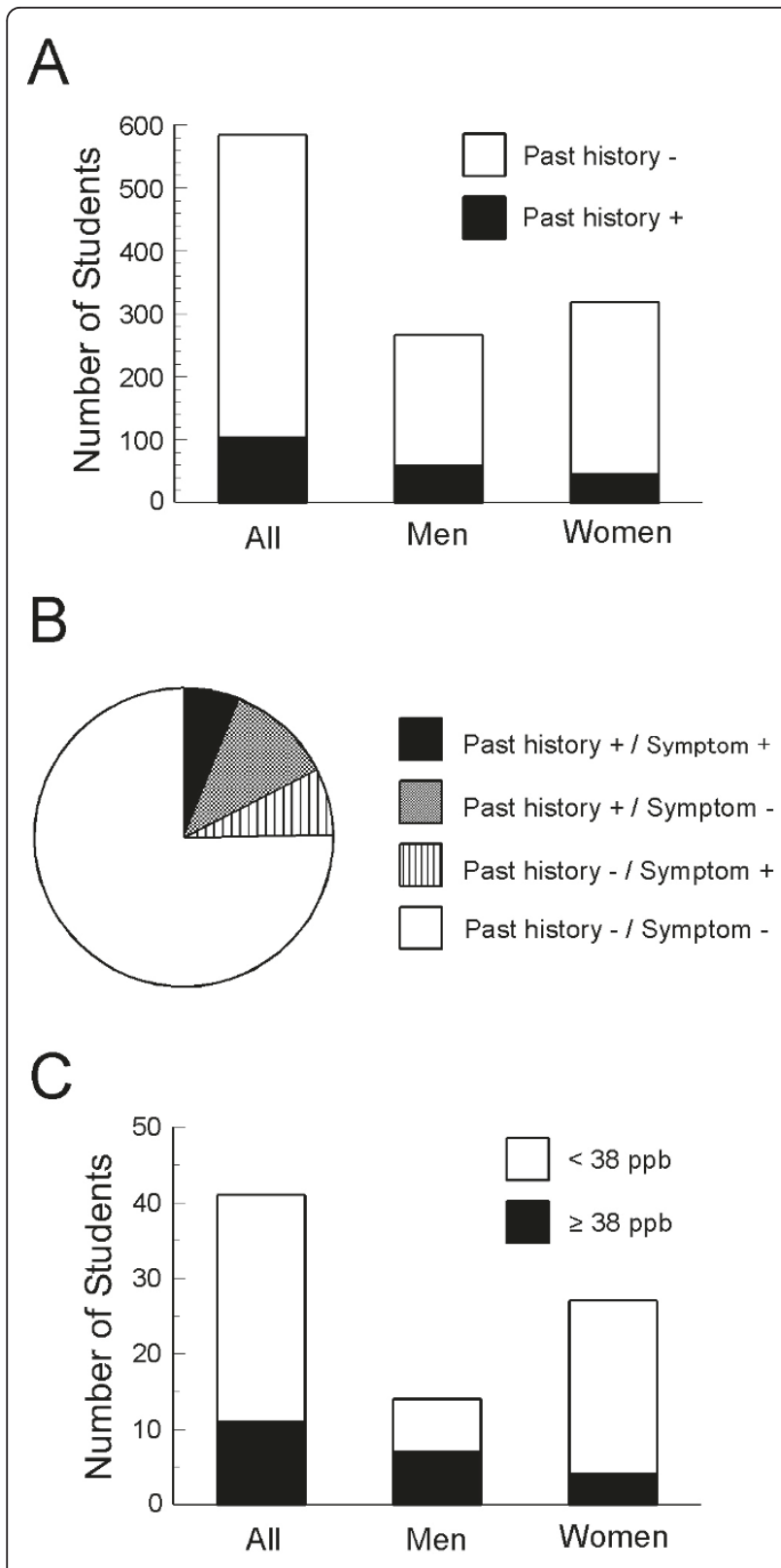

Figure $\mathbf{5}$ The relationship between past history of asthma and current symptoms of asthma. Overall, $17.6 \%$ of students ranging in age from 18 to 24 years had suffered from asthma. The percentage of students who had a past history of asthma was significantly greater in men (21.8\%) than in women (14.2\%) $(p<$ $0.05)$ (A). Of the students who had suffered from asthma, $35 \%$ had current asthma symptoms. Further, 41 (7.0\%) of 584 students ranging in age from 18 to 24 years had any asthmatic symptoms, including wheezing, a nocturnal feeling of tightness in the chest, a nocturnal attack of shortness of breath, or a nocturnal attack of cough, within the last year, although they did not have a past history of asthma (B). FENO was $\geq 38.0 \mathrm{ppb}$ in 11 of 41 students who had any asthmatic symptoms within the last year, but did not have a past history of asthma. FENO was $\geq 38.0 \mathrm{ppb}$ in 7 of 14 male students and 4 of 27 female students. The percentage of these 41 students whose FENO was $\geq 38.0 \mathrm{ppb}$ was significantly greater in men than in women $(p<0.05)(C)$. sensitive and specific symptom for the diagnosis of asthma [21]. Although a few studies have described gender differences in asthmatic symptoms [22-24], a nocturnal cough attack was observed significantly more often in women than in men in our survey as well as a previous study in Australia [22]. Less than 30\% of subjects who had a nocturnal attack of cough had an FENO $\geq 38.0 \mathrm{ppb}$. It was even smaller when subjects were limited to women. This suggests that a nocturnal cough attack as a subjective symptom is not closely related to the presence of chronic eosinophilic airway inflammation that is characteristic for typical asthma. Although a cough attack disturbing sleep is also one of the important symptoms that indicates asthma [22,25], it might be risky to make diagnosis of asthma based on this symptom especially in women.

In our study, FENO was significantly higher in men than in women aged between 18 to 24 years. Similarly, it has been reported that FENO was significantly higher in males than in females, in healthy children and healthy adults [26-29]. However, there are also some reports that deny the gender difference of FENO [30-35]. Thus, the influence of gender on FENO is still a matter of some controversy. Because gender difference in FENO was observed in our study, we tried to construct the ROC curve separately for males and females. When $44.0 \mathrm{ppb}$ was used as the cut-off value for men and $37.0 \mathrm{ppb}$ was for women, both sensitivity and specificity were much the same between men and women. We reanalyzed all data by using the gender-specific cut-off value to make assurance doubly sure. As a result, only one man was excluded from asthma and only one woman was included in asthma. Namely, the man who had experienced a cough attack was not considered to have asthma because his FENO was 38.4 ppb and the woman who had experienced wheezing was considered to have asthma because her FENO was $37.5 \mathrm{ppb}$. When we used the gender-specific cut-off value, FENO levels were the cut-off value and over in $34.8 \%$ of 266 male students and $26.1 \%$ of 318 female students. The percentage was significantly greater in men than in women $(p<0.05)$. Therefore, the results in our study did not change so much even if we used the gender-specific cut-off value.

In general, boys have a higher current prevalence of asthma than girls. This trend is reversed in adulthood, such that males have a lower prevalence than females. Actually, the percentage of students with a past history of asthma was higher in male students than in female students in our study. Gender differences in both FENO levels and a past history of asthma might mean that eosinophilic airway inflammation induced by prolongation of childhood asthma is currently present more in men than in women aged 18 to 24 years. Of students in this age group who had suffered from and still had asthma, only 3 
students were treated well, and 36 students still had asthma symptoms within the last year, which suggests that this is a problem for patients in this age group. Furthermore, about two thirds of 36 students did not see a doctor at the time of our survey. We assume that at least 11 students who did not recognize themselves as having asthma probably did have asthma because their FENO levels were over $38.0 \mathrm{ppb}$ and they had asthmatic symptoms within the last year. These students should be also recommended to see a doctor.

There are many other factors that can influence FENO levels [9]. In our study, many students had nasal allergy and it may affect FENO levels [36,37]. As expected, FENO was significantly higher in students who had any nasal allergies including hay fever than in other students. Interestingly, gender difference was not observed in the prevalence of nasal allergy on the basis of the questionnaire. Although Asian race may be a factor which increases FENO levels [38], most subjects were Japanese in this study.

The prevalence of asthma based on subjective asthmatic symptoms was $13.2 \%$ in university students ranging in age from 18 to 24 years when we estimated the maximum potential prevalence. The prevalence in female students exceeded that in male students by 1.4 percentage points. When the prevalence of asthma for the last year was estimated on the basis of FENO levels, as well as subjective asthmatic symptoms, it was $7.2 \%$. Interestingly, the prevalence of asthma symptoms estimated by considering FENO in men exceeded that in women by 4.1 percentage points. This indicates that prevalence of asthma may be estimated more objectively by considering both asthma symptoms and the degree of eosinophilic airway inflammation. Patients with asthma in this age group need to be adequately diagnosed and treated well.

\section{Conclusions}

The prevalence of asthma symptoms in university students in Japan in a single year was $7.2 \%$, estimated on the basis of FENO levels as well as subjective asthmatic symptoms. The prevalence, based on both of these factors, was higher in men than in women. Gender differences were observed in both FENO levels and asthma symptoms.

\section{Additional material}

Additional file 1: The ROC curve constructed using FENO data in university students. The ROC curve was constructed using FENO data obtained from 504 students in this study (including the samples obtained from students who were $\geq 25$ years old). The asthmatic subjects included 38 students who answered that they suffered from asthma and had wheezing in the last year. The control subjects included 466 students who answered that they did not suffer from asthma and did not have any asthmatic symptoms, including wheezing, a nocturnal feeling of tightness in the chest, a nocturnal attack of shortness of breath, or a nocturnal attack of cough in the last year, and had not experienced chronic bronchitis-like symptoms, coughing and phlegm on most days for a minimum of 3 months a year and for at least 2 successive years.

\section{List of abbreviations}

ECRHS: European Community Respiratory Health Survey; FENO: The fractional concentration of nitric oxide in exhaled air.

\section{Acknowledgements and Funding}

The authors are grateful to Dr. Akira Akasawa (National Center for Child Health and Development, Japan) and Dr. Junko Watanabe (National Hospital Organization, Sagamihara National Hospital, Japan) for permitting us to use a Japanese version of the ECRHS questionnaire. We thank Miss Hiroka Murai, a student of Gunma University School of Medicine, for her assistance on the date analysis. This work was partly supported by Health and Labour Science Research Grants (main investigator: Takahiro Tsuburai, M.D.)

\section{Author details}

'Department of Medicine and Molecular Science, Gunma University Graduate School of Medicine, 3-39-15 Showa-machi, Maebashi 371-8511, Japan. ${ }^{2}$ Clinical Research Center for Allergy and Rheumatology, National Hospital Organization, Sagamihara National Hospital, 18-1 Sakuradai, Sagamihara, Kanagawa 228-8522, Japan. ${ }^{3}$ Gunma University Graduate School of Health Sciences, 3-39-15 Showa-machi, Maebashi 371-8511, Japan. ${ }^{4}$ Health and Medical Center, Gunma University, 4-2 Aramaki-machi, Maebashi 3718510, Japan.

\section{Authors' contributions}

Intellectual planning of the project was mainly done by $T I . T H, K O, K D, T$, $K A$, and MM participated in the design of the study. Actual experimental works were performed by $\mathrm{TI}, \mathrm{SM}, \mathrm{HA}, \mathrm{MY}$, and $\mathrm{YK}$. TH, TT, and KA were involved in the development of methods for FENO measurements. All authors read and approved the final manuscript.

\section{Authors' information}

All authors are Doctor of Medicine. $T I, T H, K D$, and $K A$ are representatives of the Japanese Society of Allergology. $T I, S M, T H, T T, K D$, and $K A$ are medical specialists approved by the Japanese Society of Allergology. TI is an associate professor of Gunma University Graduate School of Medicine and a clinical professor of Gunma University Hospital. SM, HA, MY and YK are research fellows in Gunma University Graduate School of Medicine. TH is an assistant professor of Gunma University Graduate School of Medicine. TT is on the faculty of Sagamihara National Hospital. KD is a professor of Gunma University Graduate School of Health Sciences. KO is a professor of Health and Medical Center, Gunma University. KA is the chief executive officer of the Japanese Society of Allergology and the director of Sagamihara National Hospital. MM is a professor of Gunma University Graduate School of Medicine.

\section{Competing interests}

The authors declare that they have no competing interests.

Received: 16 June 2011 Accepted: 19 September 2011

Published: 19 September 2011

\section{References}

1. Taylor DR, Pijnenburg MW, Smith AD, De Jongste JC: Exhaled nitric oxide measurements: clinical application and interpretation. Thorax 2006, 61(9):817-827.

2. Rodway GW, Choi J, Hoffman LA, Sethi JM: Exhaled nitric oxide in the diagnosis and management of asthma: clinical implications. Chron Respir Dis 2009, 6(1):19-29.

3. Smith AD, Cowan JO, Brassett KP, Herbison GP, Taylor DR: Use of exhaled nitric oxide measurements to guide treatment in chronic asthma. $N$ Engl J Med 2005, 352(21):2163-2173.

4. Kharitonov $S A$, Yates $D$, Robbins RA, Logan-Sinclair R, Shinebourne EA, Barnes PJ: Increased nitric oxide in exhaled air of asthmatic patients. Lancet 1994, 343(8890):133-135. 
5. Pedrosa M, Cancelliere N, Barranco P, Lopez-Carrasco V, Quirce S: Usefulness of exhaled nitric oxide for diagnosing asthma. J Asthma 2010, 47(7):817-821.

6. Sato $S$, Saito J, Sato $Y$, Ishii T, Xintao W, Tanino Y, Ishida T, Munakata M: Clinical usefulness of fractional exhaled nitric oxide for diagnosing prolonged cough. Respir Med 2008, 102(10):1452-1459.

7. Heffler E, Guida G, Marsico P, Bergia R, Bommarito L, Ferrero N, Nebiolo F, De Stefani A, Usai A, Bucca C, Rolla G: Exhaled nitric oxide as a diagnostic test for asthma in rhinitic patients with asthmatic symptoms. Respir Med 2006, 100(11):1981-1987.

8. Chatkin JM, Ansarin K, Silkoff PE, McClean P, Gutierrez C, Zamel N, Chapman KR: Exhaled nitric oxide as a noninvasive assessment of chronic cough. Am J Respir Crit Care Med 1999, 159(6):1810-1813.

9. ATS/ERS recommendations for standardized procedures for the online and offline measurement of exhaled lower respiratory nitric oxide and nasal nitric oxide, 2005. Am J Respir Crit Care Med 2005, 171(8):912-930.

10. Saito J, Sato S, Hasunuma H, Ishimaru Y, Kanegae H, Kudo S, Munakata M: Off-line fractional exhaled nitric oxide measurement is useful to screen allergic airway inflammation in an adult population. J Asthma 2007, 44(10):805-810.

11. Tsuburai T, Tsurikisawa N, Morita $S$, Hasunuma $H$, Kanegae $H$, Ishimaru $Y$, Fukutomi Y, Tanimoto H, Ono E, Oshikata C, Sekiya K, Otomo M, Maeda Y, Taniguchi M, Ikehara K, Akiyama K: Relationship between exhaled nitric oxide measured by two offline methods and bronchial hyperresponsiveness in Japanese adults with asthma. Allergol Int 2008, 57(3):223-229.

12. Burney P, Malmberg E, Chinn S, Jarvis D, Luczynska C, Lai E: The distribution of total and specific serum IgE in the European Community Respiratory Health Survey. J Allergy Clin Immunol 1997, 99(3):314-322.

13. Peat JK, Gray EJ, Mellis CM, Leeder SR, Woolcock AJ: Differences in airway responsiveness between children and adults living in the same environment: an epidemiological study in two regions of New South Wales. Eur Respir J 1994, 7(10):1805-1813.

14. Veale AJ, Peat JK, Tovey ER, Salome CM, Thompson JE, Woolcock AJ: Asthma and atopy in four rural Australian aboriginal communities. Med J Aust 1996, 165(4):192-196.

15. Chinn S, Burney P, Jarvis D, Luczynska C: Variation in bronchial responsiveness in the European Community Respiratory Health Survey (ECRHS). Eur Respir J 1997, 10(11):2495-2501.

16. Variations in the prevalence of respiratory symptoms, self-reported asthma attacks, and use of asthma medication in the European Community Respiratory Health Survey (ECRHS). Eur Respir J 1996, 9(4):687-695.

17. Devereux G, Ayatollahi T, Ward R, Bromly C, Bourke SJ, Stenton SC, Hendrick DJ: Asthma, airways responsiveness and air pollution in two contrasting districts of northern England. Thorax 1996, 51(2):169-174.

18. Watanabe J, Taniguchi M, Takahashi K, Nakagawa T, Ooya Y, Akazawa A, Akiyama K: Validation of ECRHS Questionnaire in Japanese to use for nation-wide prevalence study of adult asthma. Arerugi 2006, 55(11):1421-1428, in Japanese.

19. de Marco R, Zanolin ME, Accordini S, Signorelli D, Marinoni A, Bugiani M, Lo Cascio V, Woods R, Burney P: A new questionnaire for the repeat of the first stage of the European Community Respiratory Health Survey: a pilot study. Eur Respir J 1999, 14(5):1044-1048.

20. Lougheed MD, Lemiere C, Dell SD, Ducharme FM, Fitzgerald JM, Leigh R, Licskai C, Rowe BH, Bowie D, Becker A, Boulet LP: Canadian Thoracic Society Asthma Management Continuum-2010 Consensus Summary for children six years of age and over, and adults. Can Respir J 2010, 17(1):15-24.

21. Sistek D, Tschopp JM, Schindler C, Brutsche M, Ackermann-Liebrich U, Perruchoud AP, Leuenberger P: Clinical diagnosis of current asthma: predictive value of respiratory symptoms in the SAPALDIA study. Swiss Study on Air Pollution and Lung Diseases in Adults. Eur Respir J 2001, 17(2):214-219.

22. Abramson M, Kutin J, Czarny D, Walters EH: The prevalence of asthma and respiratory symptoms among young adults: is it increasing in Australia? J Asthma 1996, 33(3):189-196

23. Henriksen $\mathrm{AH}$, Holmen $\mathrm{TL}$, Bjermer L: Gender differences in asthma prevalence may depend on how asthma is defined. Respir Med 2003, 97(5):491-497.
24. Almqvist $C$, Worm $M$, Leynaert $B$ : Impact of gender on asthma in childhood and adolescence: a GA2LEN review. Allergy 2008, 63(1):47-57.

25. Amdekar YK: Cough and asthma. Indian J Pediatr 2001, 68(Suppl 2):S20-25.

26. Kim SH, Kim TH, Sohn JW, Yoon HJ, Shin DH, Park SS: Reference values and determinants of exhaled nitric oxide in healthy Korean adults. $J$ Asthma 2010, 47(5):563-567.

27. Olivieri M, Talamini G, Corradi M, Perbellini L, Mutti A, Tantucci C, Malerba M: Reference values for exhaled nitric oxide (reveno) study. Respir Res 2006, 7:94

28. Travers J, Marsh S, Aldington S, Williams M, Shirtcliffe P, Pritchard A, Weatherall M, Beasley R: Reference ranges for exhaled nitric oxide derived from a random community survey of adults. Am J Respir Crit Care Med 2007, 176(3):238-242.

29. Wong GW, Liu EK, Leung TF, Yung E, Ko FW, Hui DS, Fok TF, Lai CK: High levels and gender difference of exhaled nitric oxide in Chinese schoolchildren. Clin Exp Allergy 2005, 35(7):889-893.

30. Olin AC, Rosengren A, Thelle DS, Lissner L, Bake B, Toren K: Height, age, and atopy are associated with fraction of exhaled nitric oxide in a large adult general population sample. Chest 2006, 130(5):1319-1325.

31. Matsunaga $K$, Hirano $T$, Kawayama T, Tsuburai $T$, Nagase $H$, Aizawa $H$, Akiyama K, Ohta K, Ichinose M: Reference ranges for exhaled nitric oxide fraction in healthy Japanese adult population. Allergol Int 2010, 59(4):363-367.

32. Kovesi T, Kulka R, Dales R: Exhaled nitric oxide concentration is affected by age, height, and race in healthy 9 - to 12 -year-old children. Chest 2008, 133(1):169-175

33. Silva R, Cruz L, Vieira T, Leblanc A, Ferreira A, Fonseca J, Moreira A, CastelBranco MG: Prevalence of aeroallergen sensitization and increased exhaled nitric oxide values in schoolchildren of different socioeconomic status. J Investig Allergol Clin Immunol 2010, 20(3):210-213.

34. Malmberg LP, Petays T, Haahtela T, Laatikainen $T$, Jousilahti $P$, Vartiainen $E$, Makela MJ: Exhaled nitric oxide in healthy nonatopic school-age children: determinants and height-adjusted reference values. Pediatr Pulmonol 2006, 41(7):635-642

35. Latzin P, Beck J, Griese M: Exhaled nitric oxide in healthy children: variability and a lack of correlation with atopy. Pediatr Allergy Immunol 2002, 13(1):37-46.

36. Bergmann-Hug K, Wirth R, Henseler M, Helbling A, Pichler WJ, Schnyder B: Effect of natural seasonal pollen exposure and repeated nasal allergen provocations on elevation of exhaled nitric oxide. Allergy 2009, 64(11):1629-1634.

37. Olin AC, Alving K, Toren K: Exhaled nitric oxide: relation to sensitization and respiratory symptoms. Clin Exp Allergy 2004, 34(2):221-226.

38. Kovesi $T$, Kulka R, Dales R: Exhaled nitric oxide concentration is affected by age, height, and race in healthy 9 - to 12 -year-old children. Chest 2008, 133(1):169-175

doi:10.1186/1710-1492-7-15

Cite this article as: Ishizuka et al:: Prevalence of asthma symptoms based on the European Community Respiratory Health Survey questionnaire and FENO in university students: gender differences in symptoms and FeNO. Allergy, Asthma \& Clinical Immunology 2011 7:15.

\section{Submit your next manuscript to BioMed Central and take full advantage of:}

- Convenient online submission

- Thorough peer review

- No space constraints or color figure charges

- Immediate publication on acceptance

- Inclusion in PubMed, CAS, Scopus and Google Scholar

- Research which is freely available for redistribution 